\title{
Intermediate anorectal malformation
}

INSERM

\section{Source}

INSERM. (1999). Orphanet: an online rare disease and orphan drug data base.

Intermediate anorectal malformation. ORPHA:171208

Intermediate anorectal malformation is a rare, genetic, non-syndromic subtype of anorectal malformation, resulting from a developmental defect during embryogenesis, characterized by a wide spectrum of anorectal anomalies lying between the pubococcygeal line and the ischial tuberosity (e.g., rectovestibular and rectovaginal fistulas in the female, rectobulbar fistula in the male, and anal agenesis). Patients may present with failure to pass meconium, failure to thrive, and recurrent urinary tract infections. 